\title{
Tigridia martinezii, una especie nueva de iridáceas del estado de Hidalgo (México) ${ }^{1}$
}

\author{
Graciela Calderón de Rzedowski²
}

\begin{abstract}
RESUMEN. Se describe una especie nueva de Tigridia (Iridaceae) con base en ejemplares colectados en la sierra de Pachuca, estado de Hidalgo. Tigridia martinezii pertenece al complejo VanHouttei dentro del subgénero Hydrotaenia (según el criterio de Molseed, 1970) y es aparentemente T. molseediana Ravenna, de las montañas de Oaxaca y Guatemala, la especie'con la que tiene mayor afinidad.
\end{abstract}

ABSTRACT. A new species of Tigridia (Iridaceae) is described, on the basis of collections made in the sierra de Pachuca, State of Hidalgo. Tigridia martinezii belongs to the VanHouttei complex within the subgenus Hydrotaenia (Molseed, 1970) and seems to be closely related to $T$. molseediana Ravenna, known from the mountains of Oaxaca and Guatemala.

En el transcurso de las numerosas exploraciones botánicas efectuadas para la preparación de la Flora Fanerogámica del Valle de México, se colectaron unos ejemplares pertenecientes al género Tigridia, en un par de localidades de la sierra de Pachuca (Hidalgo), que parecieron diferentes a las especies ya conocidas de este género. Al revisar la literatura correspondiente, cuya base la constituye el magnífico trabajo de Molseed (1970), se llegó a la conclusión de que en efecto se trata de un taxon nuevo para la ciencia.

Tigridia martinezii Calderón, sp. n. (fig. 1)

Herba perennis erecta, usque ad $75 \mathrm{~cm}$ alta; bulbo ovoideo; foliis lineari-lanceolatis; flos triangularis a fronte visus, usque ad $2 \mathrm{~cm}$ latus; tepala conniventia et basi cupulam formantia, breviter

\footnotetext{
${ }^{1}$ Este trabajo fue parcialmente subvencionado por el Consejo Nacional de Ciencia y Tecnología.

${ }^{2}$ Instituto de Ecología, A.C., Centro Regional de Bajío; Apdo. Postal 386; 61600 Pátzcuaro, Michoacán, México, y Laboratorio de Botánica Fanerogámica, Escuela Nacional de Ciencias Biológicas, IPN. Becario de la COFAA del IPN.
} 


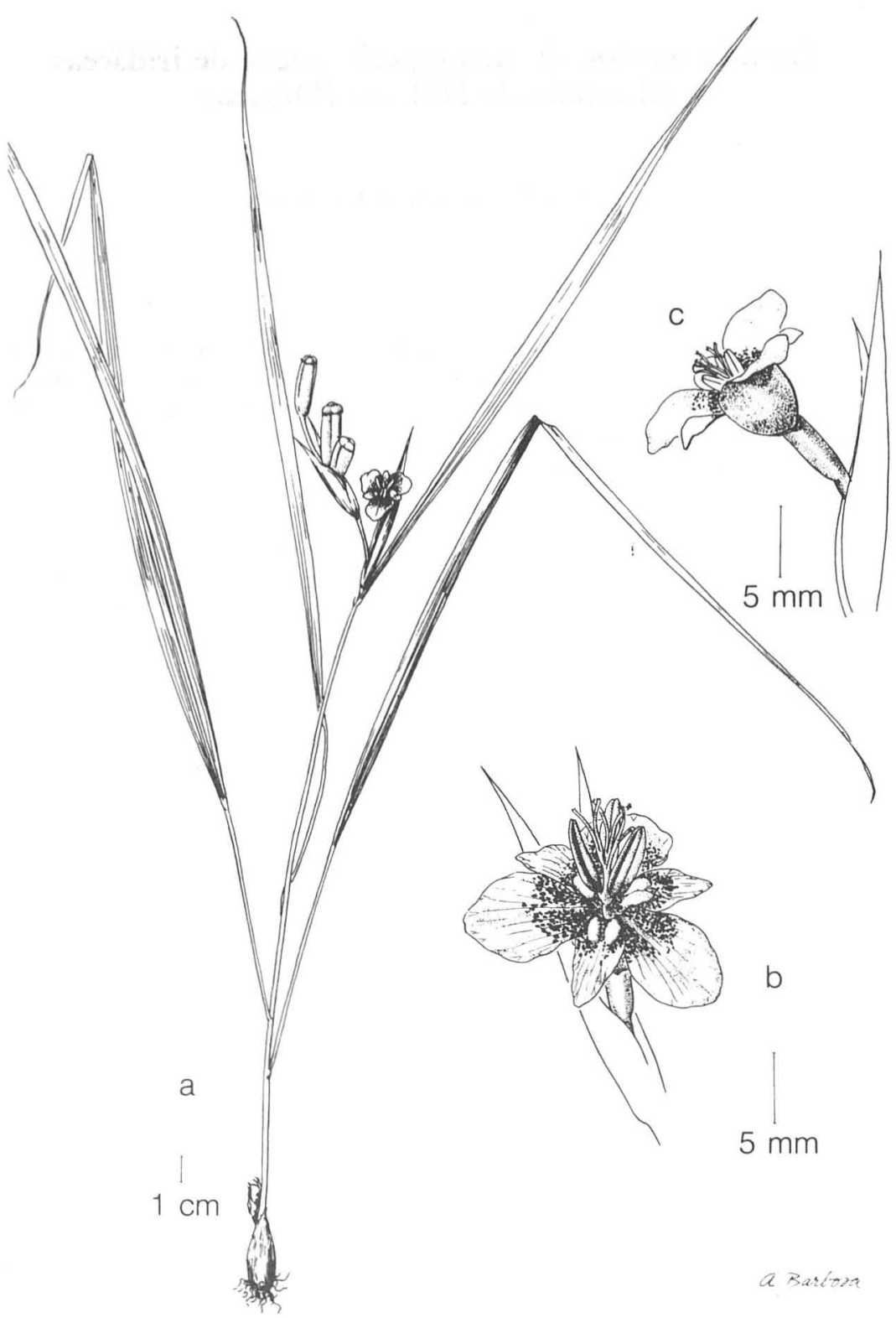

Fig. 1. Tigridia martinezii Calderón, sp. n. a: aspecto general de la planta. b: flor vista de frente. c: flor vista de perfil. 
unguiculata, cremea, in parte crateriformi purpureo-punctata; tepala externa oblonga, 1.5.-1.7 cm longa, ${ }^{7} \mathrm{~mm}$ lata; tepala interna lanceolata, ca. $1 \mathrm{~cm}$ longa, 3-4 mm lata, glans ad tepali basem posita, ex duabus maculis constans, maculae albae, ovales, apicem versus convergentes; tubus staminalis 3-4 mm longus, antherae oblongae, ${ }^{ \pm} 3 \mathrm{~mm}$ longae; stylus inter ramis emucronatus, rami $\pm 4 \mathrm{~mm}$ longi.

TIPO: MÉXICO. Estado de Hidalgo: Alrededores del cerro de las Ventanas, municipio de El Chico; zona rocosa en la parte alta de un cerro; alt. 2900 m; 29-VII-1984; Rzedowski 38428 (HOLOTIPO: ENCB). Los isotipos están por distribuirse.

Planta herbácea perenne, hasta de $75 \mathrm{~cm}$ de alto. Bulbo ovoide de alrededor de 3 $\mathrm{cm}$ de largo por 1 a $1.5 \mathrm{~cm}$ de ancho. Hojas linear-lanceoladas, plegadas, las basales de 30 a $75 \mathrm{~cm}$ de largo por 3 a $8 \mathrm{~mm}$ de ancho, las superiores de dimensiones menores. Espatas por lo general 1 o 2 por individuo, sobrepasadas considerablemente en largo por las hojas; valvas de la espata linear-lanceoladas, naviculares, de unos $3 \mathrm{~cm}$ de largo por $\pm 0.4 \mathrm{~cm}$ de ancho, encerrando varias (hasta 4) flores. Flor erecta o patente (no péndula), saliendo a ras de la espata (sin pedicelo evidente), triangular en contorno general (vista de frente), hasta de $2 \mathrm{~cm}$ de ancho. Tépalos conniventes a modo de copa en la base, cortamente unguiculados en la base, en la parte distal extendidos o algo reflejos, romos y a veces apiculados o retusos en el ápice, de color crema con puntos o líneas cortas morados o morado-cafés, dispuestos en la porción crateriforme; tépalos externos oblongos, de 1.5 a $1.7 \mathrm{~cm}$ de largo por $\pm 7 \mathrm{~mm}$ de ancho; tépalos internos lanceolados, de alrededor de $1 \mathrm{~cm}$ de largo por 3 a $4 \mathrm{~mm}$ de ancho, cada uno con glándula (superficie nectarífera) en su base, representada por un par de manchas blancas, ovales, convergentes en dirección al ápice. Tubo estaminal blanco, de 3 o $4 \mathrm{~mm}$ de largo, anteras moradas, oblongas, de $\pm 3 \mathrm{~mm}$ de largo. Estilo sin mucrón entre sus ramas, éstas de $\pm 4 \mathrm{~mm}$ de largo, bífidas en el tercio superior. Cápsula madura oblonga, de 1.8 a $2.5 \mathrm{~cm}$ de largo por $\pm 8 \mathrm{~mm}$ de ancho. Semillas subglobosas a piriformes, de unos $2 \mathrm{~mm}$ de largo, de color café claro. Se ha visto floreciendo en julio y agosto.

Otras colecciones revisadas: MÉXICO. ESTADO DE HIDALGO. Alrededores del cerro de las Ventanas, municipio de El Chico; zona rocosa con vegetación de matorral; alt. 3000 m; 24-VIII-1983; Rzedowski 38192 (ENCB); ejemplares con fruto joven. Parte alta del cerro Zumate, cerca de Pueblo Nuevo, municipio de Real del Monte; zonas peñascosas; alt. 3000 m; 21-VIII-1983; Rzedwoski 38181 (ENCB). Ibid., 5-VIII-1984; Rzedowski 38440 (ENCB).

Conocida hasta la fecha solamente de dos localidades cercanas entre sí de la sierra de Pachuca. Planta escasa, en pequeñas poblaciones, habitando en lugares de difícil acceso en la cima rocosa de cerros, de preferencia a la orilla de grietas.

De acuerdo con el criterio de Molseed (1970), Tigridia martinezii pertenece al subgénero Hydrotaenia por presentar una superficie nectarífera definida ("glándula"), evidente en material fresco a modo de una faja en los tépalos interiores. Dentro de este subgénero, correspondería al polimórfico complejo VanHouttei, tomando en cuenta que las dos series de tépalos son manifiestamente desiguales, con una uña corta basal.

En apariencia la especie con la que está más estrechamente relacionada es $T$. molseediana Ravenna, conocida de las montañas de Oaxaca y Guatemala, a más de $3000 \mathrm{~m}$ de altitud. Ambas se asemejan en: a) el porte, forma general y colores de la flor; b) la forma, color y disposición de las glándulas en los tépalos internos; y c) la ausencia de mucrón en el seno entre las ramas de los estilos (característica que solamente se presenta 


\section{Cuadro de semejanzas y diferencias entre \\ T. molseediana y T. martinezii}

\begin{tabular}{|c|c|c|}
\hline & T. molseediana & T. martinezii \\
\hline $\begin{array}{l}\text {-Flores no péndulas, tépalos } \\
\text { conniventes a modo de copa en } \\
\text { la base, de color crema con pun- } \\
\text { tos morados o morado-cafés } \\
\text { - Glándulas de los tépalos in- } \\
\text { ternos en forma de dos manchas } \\
\text { blancas, contrastantes, conni- } \\
\text { ventes hacia la parte superior } \\
\text { - Ausencia de mucrón en el } \\
\text { seno entre las ramas del estilo }\end{array}$ & $\begin{array}{l}\bullet \\
\bullet \\
\bullet \\
\bullet\end{array}$ & $\begin{array}{l}\bullet \\
\bullet \\
\bullet \\
\bullet\end{array}$ \\
\hline $\begin{array}{l}\text {-Altura de la planta } \\
\text {-Amplitud de la flor } \\
\text {-Olor de la flor } \\
\text { - Manchas moradas en los té- } \\
\text { palos }\end{array}$ & $\begin{array}{l}\text { hasta de } 35 \mathrm{~cm} \\
1.5 \mathrm{~cm} \\
\text { fétido } \\
\text { predominantemente lineares, } \\
\text { distribuidas por toda la super- } \\
\text { ficie, prevaleciendo el color } \\
\text { oscuro }\end{array}$ & $\begin{array}{l}\text { hasta de } 75 \mathrm{~cm} \\
2 \mathrm{~cm} \\
\text { no perceptible } \\
\text { en su mayoría puntiformes, } \\
\text { prácticamente restringidas a } \\
\text { la porción crateriforme, pre- } \\
\text { valeciendo el color claro }\end{array}$ \\
\hline -Forma de los tépalos internos & $\begin{array}{l}\text { ovado-elípticos, lateralmente } \\
\text { convexos en la punta, con fre- } \\
\text { cuencia constreñidos }\end{array}$ & lanceolados, aplanados \\
\hline $\begin{array}{l}\text {-Proporción de la glándula en } \\
\text { el tépalo interns }\end{array}$ & $\begin{array}{l}\text { ocupa toda la altura de la por- } \\
\text { ción crateriforme }\end{array}$ & $\begin{array}{l}\text { ocupa por lo común sólo has- } \\
\text { ta la mitad de la altura de la } \\
\text { porción crateriforme }\end{array}$ \\
\hline $\begin{array}{l}\text {-Proporción del largo de las an- } \\
\text { teras con respecto a las ramas } \\
\text { del estilo }\end{array}$ & $\begin{array}{l}\text { las ramas del estilo sobrepasan } \\
\text { considerablemente en largo a } \\
\text { las anteras }\end{array}$ & $\begin{array}{l}\text { las ramas del estilo son de } \\
\text { igual largo que las anteras o } \\
\text { las sobrepasan ligeramente }\end{array}$ \\
\hline
\end{tabular}

además en T. pavonia, especie que se considera más bien alejada del complejo VanHouttei). A la vez difieren en los siguientes rasgos: a) altura de la planta y tamaño de las flores; b) presencia o ausencia de olor en las flores y distribución de los colores en las mismas; y c) forma de los tépalos interiores y tamaño del área que ocupan proporcionalmente las glándulas en los mismos.

En el cuadro se tratan de resumir las principales semejanzas y diferencias entre estas dos especies.

El nombre Tigridia martinezii se dedica a la memoria del profesor Maximino Martínez (1888-1964), oriundo de esta parte del estado de Hidalgo, maestro e investigador distinguido, autor de numerosos libros y trabajos y que ha sido $t \mathrm{n}$ gran parte el pilar de la botánica sistemática en México.

\section{LiTERATURA CITADA}

Molseed, E. 1970. The genus Tigridia (Iridaceae) of Mexico and Central America. Univ. Calif. Publ. Bot. 54:1-127. 